Short communication

\title{
Effect of low density lipoprotein on the quality of cryopreserved dog semen
}

\author{
A.S. Varela Junior ${ }^{1}$, C.D. Corcini, R.R. Ulguim, M.V.F. Alvarenga, \\ I. Bianchi, M.N. Corrêa, T. Lucia Jr., J.C. Deschamps* \\ Centro de Biotecnologia, Faculdade de Veterinária - Universidade Federal de Pelotas - UFPel, \\ Campus Universitário s/n - Caixa Postal 354 - 96010-900 - Pelotas - RS - Brazil
}

\section{A R T I C L E I N F O}

\section{Article history:}

Received 7 July 2008

Received in revised form

15 September 2008

Accepted 4 November 2008

Available online 11 November 2008

\section{Keywords:}

Low density lipoprotein

Semen extenders

Cryopreservation

Dog semen

\begin{abstract}
A B S T R A C T
Egg yolk is included in extenders for semen cryopreservation due to its protective effect against cold shock, which is attributed to the presence of low density lipoprotein (LDL). This study evaluates how semen quality is affected by using LDL as a replacement for egg yolk in extenders for cooled and frozen dog semen. In Experiment 1 , semen was extended in TRIS-glucose at $5{ }^{\circ} \mathrm{C}$, in four treatments: $20 \%$ egg yolk (T1); 6\%(T2); 8\%(T3); and 10\% LDL (T4). Sperm motility and membrane integrity after $24,48,72$ and $96 \mathrm{~h}$ and the $50 \%$ conservation rate of motile spermatozoa $(50 \mathrm{M})$ were evaluated. The $50 \mathrm{M}$ was less for T1 than for the other treatments $(P<0.01)$, but T2-T4 did not differ $(P>0.05)$. In Experiment 2, glycerol at $10 \%$ was included in the freezing extender, in treatments similar to those from Experiment 1 . Sperm motility and membrane integrity did not differ for T2, $\mathrm{T} 3$ and $\mathrm{T} 4$ at any period in Experiment 1 and after thawing in Experiment $2(P>0.05)$, but were greater for all LDL treatments than for T1 $(P<0.01)$, in both experiments. Thus, LDL can replace egg yolk in the composition of the TRIS-glucose extender for cooled or frozen dog semen.
\end{abstract}

() 2008 Elsevier B.V. All rights reserved.

\footnotetext{
* Corresponding author. Tel.: +55 533275 7588; fax: +55 5332757551.

E-mail addresses: deschamp@ufpel.edu.br, joao.deschamps@pesquisador.cnpq.br (J.C. Deschamps).

1 Current address: Instituto de Ciências Biológicas - Universidade Federal de Rio Grande - FURG, Campus Carreiros s/n - 96201-900 - Rio Grande - RS - Brazil.
} 


\section{Introduction}

The expansion of the use of cryopreserved dog semen has been limited by the occurrence of damages in both structure and function of the sperm cells, which are attributed to cold shock during cryopreservation, impairing their viability. Thus, such damage could be prevented by the inclusion of cryoprotectant substances in extenders for cooling and/or freezing sperm. Although the egg yolk is one of the most commonly used cryoprotectants (England, 1993), it includes other substances that can have negative effects on sperm motility (Pace and Graham, 1974).

The efficiency of the egg yolk as a cryoprotectant is attributed to its content of low density lipoprotein (LDL), which adheres to the sperm cell membrane (Graham and Foote, 1987; Bergeron et al., 2004), forming an interfacial film between fatty acids and water (Anton et al., 2003). The LDL would promote the entry of phospholipids and cholesterol into the cell membrane (Bergeron et al., 2004), building a complex with seminal plasma proteins, making them unavailable to function in the membrane (Manjunath et al., 2002; Bergeron et al., 2004). The inclusion of LDL purified from egg yolk in extenders was successful for cryopreservation of semen from boars (Jiang et al., 2007) and bulls (Moussa et al., 2002; Amirat et al., 2004), but it was not tested for dog semen. This study evaluated the effect of the inclusion of purified LDL as a replacement for egg yolk, in extenders for dog semen, on variables of semen quality after cooling at $5^{\circ} \mathrm{C}$ and freezing.

\section{Materials and methods}

The first experiment (EXP1) was conducted with semen cooled at $5{ }^{\circ} \mathrm{C}$. Four Cocker Spaniel dogs from a local breeder were used as semen donors with five weekly semen collections per dog. The second experiment (EXP2) was conducted with frozen semen, with addition of glycerol to the freezing extender. Semen donors were four Cocker Spaniel dogs from a local breeder (three weekly semen collections) and two German Shepherd dogs from the local police (four weekly semen collections). In both experiments, only the second fraction of the ejaculates (rich in spermatozoa) was collected, through digital manipulation (Christiansen, 1986). Only ejaculates having sperm motility (MOT) of at least $80 \%$ at the time of collection were processed. In EXP1, sperm MOT and membrane integrity (MI) were evaluated after $24,48,72$ and $96 \mathrm{~h}$ and the $50 \%$ conservation rate of motile spermatozoa (50 M) was recorded (Iguer-Ouada and Verstegen, 2001). In EXP2, sperm MOT was evaluated pre-freezing and post-thawing, whereas sperm MI was only evaluated post-thawing. Sperm MOT was estimated with an optical microscope $(200 \times)$ with phase contrast, using $10 \mu \mathrm{L}$ of semen on a slip covered with a coverslip, both pre-heated at $37^{\circ} \mathrm{C}$. Sperm MI was evaluated through the hyposmotic swelling test (Kumi-Diaka, $1993)$, based on the count of 100 cells in a Neubauer chamber, with an optical microscope $(200 \times)$ with phase contrast, to identify spermatozoa with bent or rolled tails. All evaluations were conducted by the same trained technician.

LDL was obtained from chicken eggs. Every yolk was separated from the white, put on a paper filter to remove traces of the white in the vitelline membrane and broken into a Beaker cooled in ice. The yolk's plasmatic fraction was separated as described by Mcbee and Cotterill (1979). The yolk's plasma was extracted as described by Moussa et al. (2002). In EXP1, samples were diluted 1:5 (v/v) in TRIS-glucose (Iguer-Ouada and Verstegen, 2001) at $37^{\circ} \mathrm{C}$ and then centrifuged at $800 \times \mathrm{g}$ for $5 \mathrm{~min}$. After discharging the supernatant, the pellet was re-suspended in $1 \mathrm{~mL}$ of TRIS-glucose. The sperm concentration was determined with a Neubauer chamber: all samples had $4 \times 10^{8}$ spermatozoa $/ \mathrm{mL}$. After that, semen samples were allocated to four treatments diluted 1:1 (v/v): TRIS-glucose, with inclusion of $40 \%$ of egg yolk; and $12 \%, 16 \%$ and $20 \%$ of LDL (T1, T2, T3 and T4, respectively). Thus, T1, T2, T3 and T4 had a final concentration of $20 \%$ of egg yolk, $6 \%, 8 \%$ and $10 \%$ of LDL, respectively, and all samples had $2 \times 10^{8}$ spermatozoa/mL. The tested LDL concentrations were those reported by Moussa et al. (2002). The samples were submerged in $200 \mathrm{~mL}$ of isothermal water (Linde-Forsberg and Forsberg, 1993), kept at $20^{\circ} \mathrm{C}$ for $1 \mathrm{~h}$ and, after that, cooled for $2 \mathrm{~h}$, until the temperature reached $5^{\circ} \mathrm{C}(0 \mathrm{~h})$. In EXP2, samples were re-diluted $1 / 1(\mathrm{v} / \mathrm{v})$ in treatments similar to those from EXP1, with addition of $10 \%$ of glycerol (Synth, Diadema, SP, Brazil): T1 including 20\% of egg yolk; T2, T3 and T4 including 6\%, $8 \%$, and $10 \%$ of LDL, respectively. Thus, all treatments included glycerol at $5 \%$. Semen samples remained in contact with glycerol for $10 \mathrm{~min}$. After that, samples were stored in $0.5 \mathrm{~mL}$ straws, which were exposed 
Table 1

Sperm motility (\%) by treatment for dog semen cooled at $5{ }^{\circ} \mathrm{C}$ after different storage periods (means \pm S.E.M.).

\begin{tabular}{llllll}
\hline Treatment & \multicolumn{5}{l}{ Storage period $(\mathrm{h})$} \\
\cline { 2 - 6 } & 0 & 24 & 48 & 72 & 96 \\
\hline T1 & $87.0 \pm 1.3^{\mathrm{a}}$ & $79.0 \pm 2.0^{\mathrm{a}}$ & $73.7 \pm 1.9^{\mathrm{a}}$ & $68.2 \pm 2.3^{\mathrm{a}}$ & $61.5 \pm 2.8^{\mathrm{a}}$ \\
T2 & $86.5 \pm 1.3^{\mathrm{a}}$ & $83.5 \pm 1.9^{\mathrm{b}}$ & $83.0 \pm 1.9^{\mathrm{b}}$ & $76.5 \pm 1.9^{\mathrm{b}}$ & $70.5 \pm 2.0^{\mathrm{b}}$ \\
T3 & $88.5 \pm 1.1^{\mathrm{a}}$ & $86.5 \pm 1.3^{\mathrm{b}}$ & $83.5 \pm 1.7^{\mathrm{b}}$ & $81.5 \pm 1.9^{\mathrm{b}}$ & $75.5 \pm 2.0^{\mathrm{b}}$ \\
T4 & $87.0 \pm 1.3^{\mathrm{a}}$ & $83.5 \pm 2.1^{\mathrm{b}}$ & $81.7 \pm 1.7^{\mathrm{b}}$ & $76.5 \pm 1.8^{\mathrm{b}}$ & $70.0 \pm 1.8^{\mathrm{b}}$ \\
\hline
\end{tabular}

T1: Tris-glucose plus 20\% of egg yolk; T2: Tris-glucose plus 6\% LDL; T3: Tris-glucose plus 8\% LDL; T4: Tris-glucose plus $10 \%$ LDL. Means having different superscripts (a, b) differ in the columns by at least $P<0.01$.

to steam of liquid nitrogen for $10 \mathrm{~min}$ and then submerged in liquid nitrogen. Semen thawing was conducted at $70^{\circ} \mathrm{C}$, for $8 \mathrm{~s}$. Thawed samples were diluted in $1 \mathrm{~mL}$ of TRIS-glucose at $37^{\circ} \mathrm{C}$.

The effects on sperm MOT and MI (in both experiments) and on $50 \mathrm{M}$ (in EXP1) were tested by analysis of variance with repeated measures considering: treatments; day of semen collection; treatment per collection interaction; and individual dog effect nested within treatments. Comparisons of means \pm S.E.M. were done with the LSD test. For EXP1, four linear regression models (one per treatment) were conducted to predict the variation on sperm MOT and MI as a function of the time of preservation. All analyses were conducted with the Statistix ${ }^{\circledR}$ software (2003).

\section{Results}

In EXP1, sperm MOT after collection was $94.2 \% \pm 6.2$. At $0 \mathrm{~h}$, sperm MOT did not differ $(P>0.05)$ among treatments (Table 1). For T1, sperm MOT at $5{ }^{\circ} \mathrm{C}$ was less than that for all other treatments, from 24 to $96 \mathrm{~h}(P<0.01)$, but no differences were observed among LDL treatments, in any period $(P>0.05)$. Although the mean $50 \mathrm{M}$ for T2, T3 and T4 $(204.4,212.1$ and $200.6 \mathrm{~h}$, respectively) did not differ $(P>0.05)$, all those means were greater $(P<0.01)$ than for T1 $(152.6 \pm 6.4 \mathrm{~h})$. Sperm MI was less for T1 than for the LDL treatments $(P<0.01)$, in all periods (Table 2$)$.

The linear regression models predicted that sperm MOT would decrease as the conditioning time increased, in all treatments (all $P<0.01$ ). For T1, the equation was: MOT $=90.6-0.31771(\mathrm{~h})$, with a $R^{2}$ of 0.55. The equation for T2 was: MOT $=92.45-0.27708(\mathrm{~h})\left(R^{2}=0.46\right)$. For T3, MOT would be equal to $92.75-0.17706(\mathrm{~h})$, with a $R^{2}$ equal to 0.39 . For T4, MOT would be predicted by the following equation: $92.3-0.23125(\mathrm{~h})$, with a $R^{2}$ of 0.49 . Sperm MI would also decrease as a function of time in all treatments (all $P<0.01$ ). For T1, sperm MI would be equal to $50.725-0.14562(\mathrm{~h})\left(R^{2}=0.12\right)$. For T2, sperm MI would be equal to $68.450-0.22771(\mathrm{~h})$, with a $R^{2}$ of 0.23 . Sperm MI on T3 would be predicted by the equation: $63.125-0.15562(\mathrm{~h})$, with a $R^{2}$ of 0.12 . The equation for T4 was: $\mathrm{MI}=61.775-0.17146(\mathrm{~h})$ $\left(R^{2}=0.12\right)$.

In EXP2, mean sperm MOT after collection was $87.3 \% \pm 5.5$, without differences $(P>0.5)$ for T1, T2, T3 and T4 $(80.0 \pm 1.8,80.5 \pm 1.7,81.0 \pm 1.6$ and $81.5 \pm 1.5$, respectively). Post-thawing sperm MOT was greater $(P<0.01)$ for T2, T3 and T4 $(66.5 \pm 2.1,70.0 \pm 2.0$ and $67.5 \pm 2.6$, respectively $)$ than for T1 $(55.0 \pm 2.6)$, with no differences among LDL treatments $(P>0.05)$. Post-thawing sperm MI for T2, T3

\section{Table 2}

Sperm membrane integrity (\%) by treatment for dog semen cooled at $5^{\circ} \mathrm{C}$ after different storage periods (means \pm S.E.M.).

\begin{tabular}{|c|c|c|c|c|}
\hline \multirow[t]{2}{*}{ Treatment } & \multicolumn{4}{|c|}{ Storage period (h) } \\
\hline & 24 & 48 & 72 & 96 \\
\hline $\mathrm{T} 1$ & $46.2 \pm 2.5^{\mathrm{a}}$ & $43.9 \pm 2.6^{a}$ & $42.7 \pm 2.5^{\mathrm{a}}$ & $35.0 \pm 2.1^{\mathrm{a}}$ \\
\hline $\mathrm{T} 2$ & $62.6 \pm 2.9^{b}$ & $57.0 \pm 2.9^{b}$ & $54.2 \pm 2.5^{\mathrm{b}}$ & $45.3 \pm 1.7^{b}$ \\
\hline T3 & $59.1 \pm 2.9^{b}$ & $55.0 \pm 3.2^{\mathrm{b}}$ & $54.0 \pm 2.2^{\mathrm{b}}$ & $47.0 \pm 1.9^{b}$ \\
\hline $\mathrm{T} 4$ & $57.3 \pm 3.4^{b}$ & $54.0 \pm 2.9^{b}$ & $49.4 \pm 2.3^{b}$ & $45.1 \pm 2.4^{b}$ \\
\hline
\end{tabular}

T1: Tris-glucose plus 20\% of egg yolk; T2: Tris-glucose plus 6\% LDL; T3: Tris-glucose plus 8\% LDL; T4: Tris-glucose plus $10 \%$ LDL. Means having different superscripts (a, b) differ in the columns by at least $P<0.01$. 
and T4 (38.2 $\pm 3.1,42.4 \pm 2.9$ and $39.4 \pm 2.8$, respectively) were greater $(P<0.01)$ than for T1 $(19.9 \pm 2.8)$, but it did not differ among LDL treatments $(P>0.05)$.

\section{Discussion}

Although LDL has been used as a cryoprotectant for extended semen in some species (Moussa et al., 2002; Amirat et al., 2004; Jiang et al., 2007), the present study is the first to report its use for dog semen. LDL can replace egg yolk in the composition of the TRIS-glucose extender for cryopreserved dog semen due to improvement in sperm MOT and MI. As no effect of LDL concentration was observed, even the least tested concentration could protect cryopreserved dog sperm against cold shock. However, results from the present suggest that LDL at $8 \%$ would be more effective.

The prediction of sperm MI over time emphasizes the efficiency of the cryoprotectant effect of LDL, in all three concentrations, already after $12 \mathrm{~h}$ of preservation, which would be maintained even after $96 \mathrm{~h}$. Although sperm MI would decrease over time in all treatments, the MI for the LDL treatments after $84 \mathrm{~h}$ of preservation would be similar to that observed for T1 after only $12 \mathrm{~h}$ ( $72 \mathrm{~h}$ earlier). As the $50 \mathrm{M}$ was greater for LDL treatments than for T1 in EXP1, LDL was efficient on keeping long-term viability of cryopreserved dog semen, as reported in bulls (Moussa et al., 2002). The benefit of LDL for sperm MOT over time, in all three concentrations, was also evident in the regression models, because differences for LDL treatments in comparison with T1 became evident after $48 \mathrm{~h}$ of cryopreservation. Thus, as early as after $12 \mathrm{~h}$, the LDL would already protect the sperm cell membrane against cold shock when sperm MOT would still be at acceptable levels even without LDL. At later preservation periods, however, LDL would be important for maintenance of both traits, even though the linear decrease over time would be more characteristic for sperm MOT than for MI, as indicated by the greater $R^{2}$ observed in the models for sperm MOT. That also suggests that other factors, besides time, could influence the reduction in sperm MI over time, regardless of the cryoprotectant used, but the effect of such factors on sperm MOT would be less intense when using LDL. Although distinct studies cannot be statistically compared, the mean sperm MOT for frozen semen in the LDL treatments are apparently greater than those described by Yildiz et al. (2000) using the same extender but including different sugars.

Manjunath et al. (2002), Moussa et al. (2002), Amirat et al. (2004) and Jiang et al. (2007) found that LDL protected sperm cells against cold shock by preventing the efflux of phospholipids and cholesterol from the sperm cell membrane and also by promoting the addition of phospholipids and cholesterol into the sperm cell membrane (Bergeron et al., 2004). In the LDL treatments, the improved cryoprotection may also be related to the removal of substances present in the egg yolk (granules, minerals and high density lipoproteins) that may have negative effects on sperm viability (Pace and Graham, 1974; Thérien et al., 1999). In conclusion, the replacement of egg yolk by LDL in the composition of extenders was beneficial for sperm MOT and MI of cooled and frozen dog sperm. Furthermore, for cooled semen, the use of LDL allowed the conservation of sperm MOT up to 50\% for periods longer than those observed for the control treatment.

\section{References}

Amirat, L., Tainturier, D., Jeanneau, L., Thorin, C., Gerard, O., Courtens, J.L., Anton, M., 2004. Bull semen in vitro fertility after cryopreservation using egg yolk LDL: a comparison with Optidyl, a commercial egg yolk extender. Theriogenology 61, 895-907.

Anton, M., Martinet, V., Dalgalarrondo, M., Beaumal, V., David-Briand, E., Rabesona, H., 2003. Chemical and structural characterization of low-density lipoproteins purified from hen egg yolk. Food Chem. 83, 175-183.

Bergeron, A., Crête, M.H., Brindle, Y., Manjunath, P., 2004. Low-density lipoprotein fraction from hen's egg yolk decreases the binding of the major protein of bovine seminal plasma to sperm and prevents lipid efflux from the sperm membrane. Biol. Reprod. 70, 708-717.

Christiansen, I.J., 1986. Reproduction in the Dog and Cat. Manole, São Paulo, SP, Brazil, p. 363.

England, G.C., 1993. Cryopreservation of dog semen: a review. J. Reprod. Fert. Suppl. 47, 247-255.

Graham, J.K., Foote, R.H., 1987. Effect of several lipids fatty acyl chain length and degree of unsaturation on the motility of bull spermatozoa after cold shock and freezing. Cryobiology 24, 42-52.

Iguer-Ouada, M., Verstegen, J.P., 2001. Long-term preservation of chilled canine semen: effect of commercial and laboratory prepared extenders. Theriogenology 55, 671-684.

Jiang, Z.L., Li, Q.W., Li, W.Y., Hu, J.H., Zhao, H.W., Zhang, S.S., 2007. Effect of low density lipoprotein on DNA integrity of freezing-thawing boar sperm by neutral comet assay. Anim. Reprod. Sci. 99, 401-407.

Kumi-Diaka, J., 1993. Subjecting canine semen to the hypo-osmotic test. Theriogenology 39, 1279-1289. 
Linde-Forsberg, C., Forsberg, M., 1993. Results of 527 controlled artificial inseminations in dogs. J. Reprod. Fert. Suppl. 47, 313-323. Manjunath, P., Nauc, V., Bergeron, A., Menard, M., 2002. Major proteins of bovine seminal plasma bind to the low-density lipoprotein fraction of hen's egg yolk. Biol. Reprod. 67, 1250-1258.

Mcbee, L., Cotterill, O., 1979. Ion exchange chromatography and electrophoresis of egg yolk. J. Food Sci. 44, 656-660.

Moussa, M., Marinet, V., Trimeche, A., Tainturier, D., Anton, M., 2002. Low density lipoproteins extracted from hen egg yolk by an easy method: cryoprotective effect on frozen-thawed bull semen. Theriogenology 57, 1695-1706.

Pace, M.M., Graham, E.F., 1974. Components in egg yolk which protect bovine spermatozoa during freezing. J. Anim. Sci. 39, $1144-1149$.

Statistix ${ }^{\circledR}$ 2003. Statistix ${ }^{\circledR} 8$ Analytical Software. User's Manual. Tallahassee, p. 396.

Thérien, I., Moreau, R., Manjunath, P., 1999. Bovine seminal plasma phopholipid-binding proteins stimulate phospholipid efflux from epididymal sperm. Biol. Reprod. 61, 590-598.

Yildiz, C., Kaya, A., Aksoy, M., Tekeli, T., 2000. Influence of sugar supplementation of the extender on motility, viability and acrosomal integrity of dog spermatozoa during freezing. Theriogenology 54, 579-585. 